\title{
SOBRE EL CONCEPTO DE REPRESENTACIÓN *
}

\author{
Isabel Lifante Vidal \\ Universidad de Alicante
}

RESUMEN. Este trabajo estudia el fenómeno de la representación en el Derecho. Tras distinguir entre la representatividad, la representación simbólica y la representación práctica, el trabajo se centra en este último supuesto (que englobaría los casos en los que el representante «actúa por» el representado). Atendiendo al tipo de sujeto que puede ser representado, se presentan tres tipos distintos de representación práctica que pueden encontrarse en el Derecho: la representación individual, la institucional y la colectiva. El modo de generar la relación representativa puede ser muy distinto, pero la existencia de dicha relación implicará siempre tanto un aspecto constitutivo (la atribución de los actos del representante a la esfera jurídica del representado) como un aspecto regulativo (la obligación del representante de actuar en interés del representado).

Palabras clave: representación jurídica, representación política, representación simbólica, representatividad, interés, intereses colectivos.

ABSTRACT. This paper works on the representation in Law. After distinguishing among representativeness, symbolic representation and practical representation, the paper focuses on the last one (there the representative «acts for or in the place of» the represented). Depending on the nature of the represented, three kinds of practical representation must be found in Law: individual, institutional and collective ones. There are very different ways of generating the representation relationship, but it always implies both a constitutive aspect (the consequences of the representative's acts are attributed to the represented) and a regulative aspect (the representative must act in the interest of the represented).

Keywords: legal representation, political representation, symbolic representation, representativeness, interest, collective interests.

* Fecha de recepción: 29 de junio de 2009. Fecha de aceptación: 30 de julio de 2009.

Gran parte de este trabajo fue realizado durante una estancia en la Universidad de Génova, donde tuve ocasión de discutirlo con los miembros del Dipartimento di Cultura Giuridica «Giovanni Tarello»; a todos quiero agradecerles las sugerencias y críticas que entonces me hicieron. No puedo, sin embargo, agradecer — como me hubiera gustado - a la Generalitat Valenciana el haber apoyado este proyecto, porque, en palabras del anónimo experto informante que lo evaluó: «sólo explicita un tipo de análisis, el lingüístico, y no parece percatarse de que la vía del análisis jurisprudencial es esencial para la investigación. La pretensión de esclarecer si es posible un concepto general de representación, o si el Derecho ha elaborado conceptos diferenciados en los diferentes campos especializados no parece especialmente relevante para el saber jurídico, que en todo caso está avanzando a través de las especializaciones de ese concepto iusprivatista (sic)». El juicio de este «experto» [para quien: 1) análisis lingüístico se opone a análisis jurisprudencial, 2) el concepto de representación es meramente iusprivatista, y 3) la teoría general del Derecho carece de utilidad] situó mi proyecto — del que este trabajo es resultado- en la posición 241 de un total de 255 proyectos presentados (de los cuales 234 consiguieron financiación). 


\section{LAS PALABRAS «REPRESENTACIÓN»Y «REPRESENTAR»}

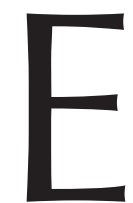

s usual señalar que el término «representación» proviene del latín repraesentare, donde quería decir «hacer presente, en algún sentido, algo que literalmente no está presente» ${ }^{1}$. Si nos preguntamos por el significado ordinario de este término hoy en día y consultamos, por ejemplo, el Diccionario de la Real Academia Española, encontraremos, entre otros, los siguientes significados para «representación»:

1. Figura, imagen o idea que sustituye a la realidad.

2. Conjunto de personas que representan a una entidad, colectividad o corporación.

3. Cosa que representa otra.

4. Derecho de una persona a ocupar, para la sucesión en una herencia o mayorazgo, el lugar de otra persona difunta.

5. Imagen o concepto en que se hace presente a la conciencia un objeto exterior $\mathrm{o}$ interior.

A su vez para el verbo «representar» encontramos — también entre otros- los siguientes significados:

1. Hacer presente algo con palabras o figuras que la imaginación retiene.

2. Sustituir a alguien o hacer sus veces, desempeñar su función o la de una entidad, empresa, etc.

3. Ser imagen o símbolo de algo, o imitarlo perfectamente.

Si nos situamos en particular en el ámbito jurídico, encontramos usos muy distintos del término representación y otros con él relacionados, tales como representar, representante, representatividad, representativo, etc. Empezaré ilustrando algunos de los usos más comunes de estos términos en los diferentes ámbitos jurídicos tomando como referencia al Derecho español.

En la Constitución Española de 1978 (en adelante CE) encontramos, por ejemplo, las siguientes referencias al concepto de representación: el Rey asume la más alta representación del Estado en las relaciones internacionales (art. $56 \mathrm{CE}$ ); la sucesión en el trono español seguirá el orden regular de primogenitura y representación (art. $57 \mathrm{CE}$ ); las Cortes Generales representan al pueblo español (art. $66 \mathrm{CE}$ ); un diputado es un representante de su circunscripción electoral (art. 68 CE) y el senado es la cámara de representación territorial (art. $69 \mathrm{CE}$ ).

Por su parte, el Derecho civil español parece operar con una distinción entre una «representación legal» y una «representación voluntaria» ${ }^{2}$. El Código Civil adjudica la representación de los hijos no emancipados a los padres, considerándola como uno de los deberes y facultades asociados a la patria potestad (arts. 154 y 1162 CC). También

1 Sobre la evolución del uso de este término puede verse el apéndice etimológico que PITKIN incorpora en su libro sobre el concepto de representación (PITKIN, 1985, pp. 269-283).

2 Así, aunque el Código Civil no define ambas categorías, en su art. 10.11 dice: «A la representación legal se aplicará la Ley reguladora de la relación jurídica de la que nacen las facultades del representante, y a la voluntaria, de no mediar sometimiento expreso, la Ley del país en donde se ejerciten las facultades conferidas». 
establece que en los casos en que una persona desaparece, el juez podrá nombrar un defensor que ampare y represente al desaparecido en juicio o en los negocios que no admitan demora (art. 181 CC), o que el tutor es el representante del menor o incapacitado, salvo para aquellos actos que pueda realizar por sí solo (art. 267 CC). En todos estos casos parece que la representación funciona como un remedio para casos de ausencia o imposibilidad de actuar de un individuo ${ }^{3}$. Estos supuestos suelen ser considerados como casos de «representación legal» frente a los supuestos que el Código Civil llama de «representación voluntaria». Con esta última expresión, parece referirse — según suele sostener la doctrina - al contrato de mandato y figuras similares, aunque no encontramos expresamente referencia alguna a la «representación», ni conceptos derivados, en la regulación de esos contratos ${ }^{4}$. Encontramos también referencias aparentemente muy distantes a estos sentidos de «representación» en el mismo Código Civil, así por ejemplo: los títulos representativos de préstamos hipotecarios tienen la consideración de cosas muebles (art. 336 CC); para la administración de la cosa común se exige acuerdo adoptado por los partícipes que representen la mayor cantidad de los intereses que constituyan el objeto de la comunidad (art. 398 CC); o los parientes de una persona tienen un derecho de representación para sucederle en todos los derechos que tendría si viviera o hubiera podido heredar (art. 924 CC). La dogmática ha elaborado también algunos conceptos que hacen referencia a usos específicos del término «representación». Así por ejemplo, en el ámbito del Derecho civil, se habla de «representación indirecta» o de «representación aparente» (cuando no hay contrato previo de mandato, pero alguien actúa en defensa de los intereses de otro ${ }^{5}$ ).

También el Derecho mercantil atribuye la representación de las sociedades (tanto anónimas como de responsabilidad limitada) a los administradores, estableciendo —en cuanto al ámbito de dicha representación - todos los actos comprendidos en el objeto social delimitado en los estatutos, tanto en juicio como fuera de él (arts. 128-129 Ley de Sociedades Anónimas; y 62-63 de la Ley de Sociedades de Responsabilidad Limitada).

En la esfera del Derecho procesal aparece otro ámbito relevante de la representación. Aquí nos encontramos con toda la regulación de la representación necesaria para comparecer en juicio; así, la Ley de Enjuiciamiento Civil española (LEC) exige, como regla general la concurrencia de un procurador al que habrá de otorgársele el poder de representación ante notario o secretario judicial (arts. 23 y 24 LEC). También en este ámbito la dogmática ha elaborado, dentro de lo que considera como «legitimación indirecta» (aquélla en la que el derecho a obtener la tutela jurisdiccional corresponde a alguien distinto del titular del derecho subjetivo que fundamenta la tutela), una categoría para la que propone precisamente el nombre de «legitimación representativa» (DE LA OLIVA, 2004, pp. 158-159), con ella se refiere, por ejemplo, a los casos en los que la Ley concede legitimación para la defensa de los intereses difusos de consumidores y usuarios exclusivamente a las «asociaciones de consumidores y usuarios que, conforme a la Ley, sean representativas» (art. 11.3 LEC).

3 Cfr. Pietro Costa, 2005, p. 15.

${ }^{4}$ Cfr. Dí́z-PiCAZO, 2004.

5 Vid., por ejemplo, GoRDillo, 1978, pp. 15 y ss., o DíEz-PiCAZO, 2004. Aunque algunos discuten que esta categoría sea realmente un tipo de «representación», precisamente por la ausencia del elemento de mandato (cfr. PugliatTi, 1965, pp. 397 y ss.). 
Por lo que respecta al ámbito del Derecho administrativo nos encontramos al menos tres contextos relevantes en los que aparece la representación: 1) al regular la representación de los órganos colegiados, encomendando la misma a sus presidentes [art. 23.1.a) de la Ley de Régimen Jurídico de las Administraciones Públicas y Procedimiento Administrativo Común; en adelante: LRJAPyPAC] y limitando la posibilidad de que los miembros de los órganos colegiados se atribuyan las funciones de representación reconocidas al órgano a los casos en que expresamente se les hayan otorgado por una norma o acuerdo válidamente adoptado, para cada caso concreto, por el propio órgano (art. 24.2 LRJAPyPAC); 2) al aceptar la posibilidad de que los interesados con capacidad de obrar puedan llevar a cabo sus actuaciones administrativas por medio de representante (art. 32 LRJAPyPAC), y 3 ) al hacer depender el régimen jurídico de los órganos colegiados del hecho de que los mismos se configuren como órganos representativos, bien por la participación en ellos de organizaciones representativas de intereses sociales, bien por estar compuestos por representaciones de distintas Administraciones Públicas ${ }^{6}$ (art. 22.2 LRJAPyPAC).

Aparte de todas estas referencias que encontramos en los textos legales o en las elaboraciones doctrinales, es usual aceptar en distintos contextos - muchos de ellos jurídicos-afirmaciones como las siguientes: 1) los sindicatos ostentan la legitimación para representar a los trabajadores; 2) un chico de 27 años que todavía vive con sus padres es representativo de los jóvenes españoles de hoy en día (al igual que «la niña de Rajoy» del debate electoral de 2008 pretendía ser la ilustración de una niña representativa de un futuro en el que el PP hubiese ganado las elecciones); 3) una institución - como pueda ser el Tribunal Constitucional o una de las Reales Academias- que apenas tenga mujeres en su composición, es criticable por ser poco representativa de la sociedad; 4) para el gobierno de casi cualquier institución es preferible un órgano representativo frente a otro que no lo sea $^{7}$, y 5) la bandera de un país lo representa; etcétera.

Pues bien, tras este rápido, y necesariamente incompleto, repaso de algunas de las referencias al término «representación» en discursos jurídicos y «parajurídicos», parece obvio que el mismo es usado con una multiplicidad de sentidos: ¿qué pueden tener en común la representación que ejerce el rey de España con la que lleva a cabo un diputado, o la que desempeña un tutor, o un procurador?; ¿’n qué sentido consideramos a un órgano o institución sin presencia de mujeres como «no representativo»?; ¿qué quiere decir que alguien pertenece a un órgano «en representación» de un determinado colectivo? Con el objetivo de intentar responder a algunas de estas preguntas presentaré en primer lugar algunos de los análisis de este fenómeno que mayor relevancia han tenido en las discusiones conceptuales contemporáneas, de los que

${ }^{6}$ En estos casos se posibilita el establecimiento de normas propias de funcionamiento y se les excluye —en principio - de su integración en la estructura jerárquica de la Administración Pública en la que se integren.

7 Puede notarse que cuando el calificativo de «representativo» se predica de un órgano, el mismo se suele utilizar con carácter elogioso, en muchas ocasiones como sinónimo de «participativo» o «democrático». En este sentido, por ejemplo, PITKIN afirma: «No cabe duda de que la actual popularidad del concepto está muy fundamentada en el hecho de aparecer vinculado a la idea de democracia, así como a las ideas de libertad y justicia. Sin embargo, en el transcurso de su historia, tanto el concepto como la práctica de la representación han tenido poco que ver con la democracia y la libertad» (PITKIN, 1985, p. 2). 
pretendo valerme en la última parte del trabajo, al ofrecer un intento de reconstrucción conceptual.

\section{CUATRO ANÁLISIS CONCEPTUALES}

\subsection{PITKIN y las dimensiones de la representación política}

Tomaré como punto de partida el análisis que H. PITKIN lleva a cabo en su libro El concepto de representación, escrito en 1967, y que sigue siendo uno de los trabajos más exhaustivos y sugerentes a propósito de este tema. Esta autora pasa revista a las diferentes descripciones que históricamente se han hecho de la representación y llega a la conclusión de que, aunque todas han captado parte de su significado, o, por así decirlo, alguna de sus dimensiones, ninguna de ellas ha sido sin embargo lo suficientemente compleja como para reflejarlo en su totalidad. Estas cinco perspectivas o dimensiones serían las siguientes ${ }^{8}$ :

R1. Representación como autorización. El representante es alguien autorizado a actuar en nombre del representado, el cual asume las consecuencias de las acciones del representante como si las hubiera realizado él mismo.

R2. Representación como responsabilidad u obligación de rendición de cuentas (accountability). La representación es una relación de agencia en la que el representante debe rendir cuentas por su actuación ante su representado.

R3. Representación como correspondencia, descripción o reflejo (o «representación descriptiva»). El representante suple al representado por medio de una correspondencia de características.

R4. Representación como identificación simbólica. El representante suple al representado por una relación basada en las actitudes y creencias de la gente.

R5. Representación como actuación por otro (o «representación sustantiva»). El representante es el que actúa en nombre de otro, en su interés o como su agente.

Los dos primeros supuestos, la representación como autorización y la representación como responsabilidad, se refieren respectivamente a la determinación de quién o qué está autorizado para representar y de quién puede ser fiscalizado como representante. En el primer supuesto la representación descansa en la idea de «concesión de autoridad sin rendir cuentas» por su actuar, acentuando la capacidad que tiene el representante de vincular a sus representados (y no tanto sus deberes u obligaciones hacia ellos). En el segundo supuesto, el de la representación como responsabilidad, se acentúa precisamente la rendición de cuentas ante el representado. Podría decirse, igualmente, que en el primer supuesto la representación aparece como un poder derivado de una autorización y en el segundo supuesto como un poder del que se tiene que responder ante otros (cfr. IBARRA, 2007).

8 Sigo aquí en gran medida la reconstrucción que realiza GARCÍA GUITIÁN (2001, pp. 215-216 y 2004 , pp. 111-112) del trabajo de PITKIN. Debe señalarse que el objetivo fundamental del análisis de PITKIN es dar cuenta de la representación política, y no tanto ofrecer un mapa conceptual general de la representación, y quizás por ello mismo este mapa ha podido ser reconstruido a partir de sus escritos de maneras muy diversas: como distintos sentidos, concepciones o dimensiones de la representación ( vid., por ejemplo, WEISSBERG, 1978; EULAU y KARPS, 1983; LAPORTA, 1989; SARTORI, 1999a y 1999b; GARCÍA GUITIÁN, 2001 y 2004; MANSBRIDGE, 2004). 
La tercera dimensión, la de la representación descriptiva, hace referencia a una correspondencia o semejanza precisa con respecto de aquello que se representa mediante un reflejo no distorsionado. Aquí — dice PITKIN — la representación depende de las características del representante, de lo que es o de lo que parece ser. El hecho de representar se encuentra, dice la autora, «en el ser algo antes que el hacer algo» (PITKIN, 1985, p. 67).

En el cuarto caso, el de la representación simbólica, se subraya la idea de «suplir» a través de algo que exprese la entidad que se representa. A diferencia del supuesto anterior, aquí la conexión entre símbolo y referente no exige semejanza o imagen alguna; se trata de una conexión de un tipo distinta y, en algún sentido - dice PITKIN—, arbitraria, dado que la misma existe únicamente donde se cree en ella, «el único criterio que rige lo que constituye un símbolo se encuentra en las actitudes y creencias de la gente» (Pitkin, 1985, p. 109). Los símbolos no guardan semejanza con sus referentes y no se les parecen, no hacen aseveraciones acerca de lo que simbolizan, sino que más bien lo sugieren ${ }^{9}$. De este modo, la representación simbólica resultaría de un proceso de formación de hábitos y de relaciones afectivas; se trataría de un modo de ser capaz de evocar la realidad representada.

Tanto en el tercer como en el cuarto caso, dice PITKIN, se trata de un fenómeno (describir o simbolizar) que puede ser realizado no sólo por personas sino también por objetos inanimados (pensemos, por ejemplo, el caso en el que se dice que una bandera representa a un país) (PitKIn, 1985, p. 13).

Por último, en el quinto supuesto, el de la representación como actuación por otro, la discusión se sitúa precisamente respecto a cómo caracterizar sustantivamente (de ahí la calificación de esta dimensión como «representación sustantiva») la actividad que debe desplegar el representante. Al representante se le ha caracterizado en ocasiones, dice PITKIN, como a una persona que despliega su actividad asumiendo alguna de las siguientes posiciones: la de un sustituto, que actúa en lugar de otro; la de un tutor, que cuida de alguien o actúa en su interés; o la de un subordinado, que actúa siguiendo las instrucciones o deseos de otro. Ninguna de ellas, sin embargo, resultaría en su opinión un equivalente satisfactorio de la idea de representación (PITKIN, 1985, p. 152). Para PITKIN el contenido sustantivo de la acción del representante se define sobre la base del interés del representado. «Representar» significa así desarrollar acciones de protección y promoción de los intereses de quien no quiere o no puede actuar en nombre propio, aunque permanece el problema de cómo entender este interés en los diversos casos de representación ${ }^{10}$.

Como hemos señalado, estos cinco supuestos son tratados por PITKIN no tanto como diferentes sentidos de «representación», sino más bien como diferentes perspectivas o dimensiones de la representación política, que compiten por ofrecer la aproximación más adecuada a la misma. Esas dimensiones, por tanto, pueden conjugarse

9 PITKIN lleva a cabo una analogía ilustrativa de la distinción entre la representación descriptiva y la simbólica a partir de las diferencias entre el arte representativo y el arte simbólico ( $c f r$. PITKIN, 1985, caps. 4 y 5 ).

10 El objetivo fundamental de la obra de PITKIN es precisamente analizar en qué debe consistir la actividad del representante (en particular en el ámbito político), cómo debe entenderse la actuación en cuidado de intereses de otro, qué concepto de interés es aquí relevante, etc. Por eso, a esta dimensión de la representación es a la que dedica los capítulos 6 a 10 de su libro. 
entre sí de diversas maneras, dependiendo del modo en que se interpreten, de que se dé mayor o menor peso a cada una de ellas o de que se configuren de uno u otro modo las relaciones entre ellas. En el fondo, esta idea nos conduce a la consideración de que la representación política, o mejor dicho, la democracia representativa cae en el ámbito de lo que GALLIE llamó conceptos esencialmente controvertidos (GALLIE, 1962). Pues bien, muchas de las teorías a propósito de cómo debe entenderse la representación política pueden verse de hecho como el intento de articular una teoría a propósito de algunas de estas dimensiones (o de todas ellas), de manera que se persigue identificar la manera correcta de entender el gobierno representativo, considerado obviamente como algo valioso, con el objetivo de poder extraer directrices para diseñar nuestras instituciones; estas teorías, podríamos decir, dan lugar a distintas concepciones del concepto de democracia representativa ${ }^{11}$.

\subsection{DigGS y la distinción entre representación descriptiva y representación práctica}

Prácticamente al mismo tiempo que PITKIN publicaba (en 1967) su libro sobre el concepto de representación, B. J. DiGGs escribió un interesante artículo que lleva por título «Practical Representation» (DigGS, 1968), en el que contrapone un concepto «descriptivo» a un concepto «práctico» de representación. Su objetivo primordial —al igual que el de PITKIN — es realizar algunas precisiones conceptuales para analizar la representación política. En opinión de DigGs hay una fuerte tendencia a pasar por alto las características comunes a las diferentes formas de representación y a interpretar la representación política de manera demasiado restringida, planteándose por ello problemas teóricos a propósito de si es realmente posible la representación en un amplio y complejo sistema político.

La idea común central a las diversas formas de representación consiste para DiGGS en que «algo o un grupo de cosas — que se dice que es "representado" - es de alguna manera "hecho presente" o "presentado" por medio de un intermediario» (DIGGS, 1968, p. 29). El intermediario puede ser de muy diverso tipo, y a partir de estas variedades de representación, DIGGS opta por presentar una contraposición entre una representación «pictórica, dramática o descriptiva», por un lado, y lo que propone llamar una representación «práctica», por otro lado. En el primer caso, dice DiGGS, el intermediario suele ser llamado una «representación» (así por ejemplo, un cuadro o una descripción), mientras que en el segundo caso decimos que el intermediario es un «representante» y — continúa DIGGS — «este tipo de representante, a diferencia de "un ejemplar representativo" ${ }^{12}$, literalmente actúa por o en lugar del representado»

11 Creo que GARCía GUITIÁN señala en esta misma dirección cuando afirma: «La representación democrática significa entonces tantas cosas como que alguien ha sido autorizado a actuar en nombre de otro [R1] por compartir determinadas características [R3] y haberse establecido entre ellos cierto vínculo emocional [R4], para que actúe en su interés o beneficio [R5], por lo cual deberá después rendir cuentas [R2]. Cada una de estas exigencias puede ser objeto de diferente interpretación y tener un mayor o menor peso en la concepción final, lo que condicionará la visión que tengamos, pero todas de alguna manera están presentes en la concepción democrática de la representación» (GARCÍA GUITIÁN, 2004, pp. 111-112).

12 Téngase en cuenta que la palabra inglesa «representative» significa tanto «representante» como «representativo», de ahí el interés de DigGs en distinguir los dos usos de la palabra. 
(DigGS, 1968, p. 29). En este caso, el representado suele ser una persona o conjunto de personas, que son vistas no como algo «a describir o contemplar», sino como portadoras de propósitos y problemas prácticos, a los cuales sirve el representante. Podría decirse que en estos casos se trata de alguien que actúa como «agente» de otras personas que son a su vez vistas como sujetos activos (es decir, también como «agentes» en otro sentido). Más adelante DigGS conecta esta idea con el hecho de que el representante ocupa un lugar, en el sentido de que desempeña un «rol».

Pero DigGS también llama la atención sobre el hecho de que no todos los casos en que alguien hace un trabajo para otro encajan en este sentido de representación práctica, sino que es necesario que el representante haga un trabajo el cual, en algún sentido, se supone que hace el propio representado, o principal. En este sentido, el representante hace un trabajo para otro como su «sustituto», aunque este nuevo concepto —el de sustituto- es a su vez impreciso y por tanto no demasiado útil para aclarar a qué nos referimos (no todos los sustitutos trabajan para el sustituido...). El principal actúa a través del representante, y en su opinión esto debe tomarse en un sentido bastante estricto: el representante «práctico» sirve como agente de otro, y puede decirse que cuando el representante actúa, el sujeto representado en algún sentido también actúa ${ }^{13}$.

DIGGS concluye que no existe un género común de lo que sería la representación, sino más bien diferentes formas de representación que comparten entre sí parecidos de familia, y por ello la distinción entre los casos en que consideramos que alguien es un representante y los que, por ejemplo, serían considerados como meros sustitutos es difícilmente explicable en términos de una lista de requisitos precisos, sino que más bien necesitamos acudir a ciertas analogías entre la representación práctica y el otro sentido de representación antes señalado: el de la representación descriptiva.

Estos dos sentidos de representación aparecen en posteriores análisis de diversos autores. Así, por ejemplo, utilizando las categorías de DigGS, LAPORTA propone distinguir entre lo que llama una representación «descriptiva» y una representación «normativa». En opinión de este autor, la primera englobaría los supuestos $R 3$ y $R 4$ del análisis de PITKIN, es decir, la representación como correspondencia, descripción o reflejo y la representación simbólica. Mientras que los otros tres supuestos (la representación como autorización, como disposición a responder y como cuidado de intereses) serían casos de representación normativa. En los primeros casos la representación es considerada descriptiva porque «el representante representa porque es algo: un símbolo o un reflejo; mientras que en los demás casos el representante representa porque tiene competencia o poder para hacer algo, o porque debe hacer algo» (LAPORTA, 1989, p. 131). También entre los teóricos del Derecho privado encontramos autores que al ocuparse del concepto de representación realizan una distinción semejante. Así, por ejemplo, DIDIER señala que pueden distinguirse dos sentidos de representación. En su primer sentido, el verbo representar designa la acción de mostrar, exhibir, presentar, enseñar..., y en todos estos casos la representación designaría un hecho. Al lado de este

13 En este punto DigGs señala sin embargo que no siempre hablamos de esta manera (1968, pp. 32-33). Diríamos por ejemplo que «alguien ha votado por poderes», pero no diríamos que «alguien ha votado cuando ha votado su representante», en todo caso en estos supuestos diríamos que «un ciudadano vota a través de su representante». Aunque creo que aquí el problema radica en si podemos considerar que el representante lo es de un ciudadano concreto; más adelante volveré sobre esta cuestión. 
primer uso de la expresión — dice DIDIER—, el Derecho conoce otro más complejo; en este segundo caso, representar es figurar. En este sentido, cuando una persona representa a otra, la «figura», le presta su cara, actúa en su lugar, es decir, la reemplaza. Actuar por representación sería, dice, realizar un acto en nombre y por cuenta de otro, en virtud de un poder (DIDIER, 2000, pp. 3-4).

\subsection{La representación «jurídica» y la representación «política» en SARTORI}

Partiendo de las cinco perspectivas o dimensiones que vimos que PITKIN distinguía en el concepto de representación, SARTORI se propone precisamente poner en relación la llamada representación política (o de Derecho público) con lo que se suele considerar como representación jurídica (o de Derecho privado).

El ámbito del Derecho privado parece ser tomado por SARTORI como el ámbito primitivo del concepto de representación y, por tanto, su extensión a otros ámbitos ha de justificarse por su analogía con éste. En el ámbito de la representación jurídica, o de Derecho privado, señala este autor, la representación se concibió y desarrolló originariamente como «una relación bipersonal (o de un grupo de personas con otra persona) entre un cliente (o un concreto grupo de clientes) y un agente designado por éste (el principal o dominus de la relación) con unas instrucciones generales. Dado que los actos del representante surten efecto para el principal, la sujeción de aquél a las instrucciones dictadas por éste era un elemento esencial de la relación de representación» (SARTORI, 1999b, p. 2). Cuando este elemento se pone en primer término — dice SARTORI - tenemos la teoría del mandato. Pero inmediatamente llama la atención sobre el hecho de que las cosas no siempre son así, ni siquiera en el ámbito del Derecho privado; así, por ejemplo, describir a un abogado como un mandatario sería muy incorrecto: los abogados deben defender los intereses de sus clientes de acuerdo con su propio juicio y competencia, «el cliente espera que su abogado se comporte responsablemente, es decir, que contribuya a la consecución de los resultados con su "responsabilidad independiente"» (SARTORI, 1999b, p. 3). Por tanto, la teoría de la representación de Derecho privado no puede identificarse con la teoría del mandato, pero tampoco - dice- desvincularse completamente de ella, pues el dominus puede siempre retirar la representación en cualquier momento a su representante.

A continuación, SARTORI analiza lo que ocurre con la representación del ámbito del Derecho público, y señala que aquí nos encontramos con que desaparecerían tanto las instrucciones vinculantes como la revocabilidad inmediata (tanto la prohibición de mandato imperativo, como la imposibilidad de sustitución hasta que expire el plazo de ejercicio de su función están hoy firmemente arraigados en la teoría de la representación política). Otra diferencia importante de tipo fáctico que señala este autor es que la representación política implica inevitablemente una relación de muchos con uno. A partir de aquí, SARTORI se plantea si en este ámbito podemos considerar que existe «verdadera representación», y su respuesta, a diferencia de la que considera que dan la mayoría de los juristas ${ }^{14}$, es que sí, porque aunque la representación política es una

14 Aquí SARTORI cita a KELSEN, señalando que según este autor sólo habría relación representativa en el ámbito privado. Esta interpretación de KELSEN, que está muy extendida ( $c f r$. GARRORENA MORALES, 1991, 
versión debilitada de su concepto originario, persisten aún suficientes analogías. Aunque no haya en estos casos un principal concreto y perfectamente identificable, la «representación electiva» trae consigo a) receptividad (responsiveness): los parlamentarios escuchan a su electorado y ceden a sus demandas; $b$ ) rendición de cuentas (accountability): los parlamentarios han de responder, aunque difusamente, de sus actos, y c) posibilidad de destitución (removility), si bien únicamente en momentos determinados, por ejemplo, mediante un castigo electoral (SARTORI, 1999b, pp. 3-4).

En opinión de SARTORI, existe un «significado originario» de representación, que sería el que se conecta con la actuación en nombre de otro en defensa de sus intereses (que vendría a coincidir precisamente con la última dimensión señalada por PITKIN, $R 5$, que era el objeto de atención prioritario de su análisis), y a partir de aquí entiende que las dos características definitorias de este concepto serían, por tanto, a) una sustitución en la que una persona habla y actúa en nombre de otra; $b$ ) bajo la condición de hacerlo en interés del representado» ${ }^{15}$ (SARTORI, 1999b, p. 2). Esta definición sería aplicable tanto al concepto de representación jurídica (que él considera ligada a la idea de mandato o delegación), como al de representación política (ligada a la idea de responsabilidad).

Pero además, señala SARTORI, en el ámbito de la política hay también un uso sociológico del término «representación» que no puede dejarse de lado sin más como una mera acepción diferente. Cuando decimos que alguien o algo es «representativo de algo» estamos expresando una idea de similitud, de identificación, de características compartidas. La exigencia de que el Parlamento sea un reflejo del país se basa en este significado del término «representación». En este sentido, aunque representación y representatividad aluden a cuestiones diferentes y son conceptos distintos, la comprensión de la política representativa depende, en su opinión, de ambos. De este modo, en opinión de SARTORI, la representación en el ámbito político puede asociarse con tres ideas distintas: a) con la idea de mandato o delegación; $b$ ) con la idea de representatividad, es decir, de semejanza o similitud, y $c$ ) con la idea de responsabilidad (SARTORI, 1999a, p. 269).

\subsection{FERRAJOLI y la representación como relación jurídica}

En su reciente teoría axiomatizada del Derecho, L. FERRAJOLI también se ha ocupado de caracterizar los conceptos de representación jurídica y de representación política; aunque, a diferencia de SARTORI, su análisis propone tratarlos como dos conceptos netamente distintos. La representación jurídica sería un tipo muy relevante de relación

pp. 44-45), creo que pasa por alto que para KELSEN toda relación representativa, y no sólo la política, implicaría una ficción si se entiende la representación como «reproducción» de una voluntad. En este mismo sentido, BRUNET, 2004, p. 5.

15 También DíEZ-PICAZo considera que el elemento central y definitorio de la representación en el ámbito del Derecho privado (que es del que exclusivamente se ocupa este autor) sería el actuar en interés de otro: «No toda colaboración que se presta a otro se sitúa dentro de la idea de representación. Esta es una forma muy concreta de cooperación: aquella que consiste en la gestión y cuidado de bienes y de intereses ajenos [...] la idea que ilumina decisivamente el fenómeno de la representación es la idea de gestión de asuntos ajenos» (Díez-PicAzo, 1979, p. 63). 
jurídica que aparece en todos aquellos casos — muy numerosos en el Derecho- en los que no existe coincidencia entre el autor de un acto y el titular de la situación activa de la cual el acto es actuación. Siguiendo su método axiomático, FERRAJOLI propone una definición de «representación», y a partir de ella de «representante» y «representado», en los siguientes términos:

«Representación es la relación jurídica en virtud de la cual un sujeto jurídico está obligado a satisfacer las expectativas y a tutelar los intereses de otro sujeto, al cual son imputables los actos realizados por el primero en actuación de situaciones de las cuales el segundo es titular, sin que entre los dos quepa ningún conflicto de intereses.

(...) Representante es el sujeto jurídico ligado por una relación jurídica a otro sujeto en cuyos intereses, y sin posibilidad de conflicto con los propios, debe cumplir los actos a él imputables en actuación de las situaciones de las cuales es titular.

(...) Representado es el sujeto jurídico ligado por una relación jurídica a otro sujeto en relación con el cual tiene la expectativa de que cumpla en su interés, y sin posibilidad de conflicto con los suyos, los actos que le son imputados en actuación de las situaciones de las cuales es titular» (FERRAJOLI, 2007, vol. I, p. 371).

El representante es investido de unas situaciones de poder-deber, «funciones», que pueden presentar distinta naturaleza dependiendo del tipo de sujeto representado y del acto institutivo de la representación. En este sentido, y siguiendo la terminología tradicional, propone distinguir tres tipos de representación. La primera sería una «representación voluntaria o negocial», que sería aquélla en la que la relación representativa está instituida por efecto de un poder, lo que presupone necesariamente, en cuanto acto de voluntad negocial, la capacidad de actuar del representado. La segunda sería la llamada «representación necesaria o legal», que se daría en aquellos casos en los que la relación es instituida ex lege para la tutela de personas naturales incapaces de actuar. Y, por último, estaría la «representación orgánica o institucional», que sería igualmente necesaria, y que designaría la relación representativa instituida entre un funcionario y una persona jurídica, a la que considera igualmente incapaz. Naturalmente - dice FERRAJOLI - estas tres formas de representación son caracterizadas con un diverso grado de fuerza vinculante. En la voluntaria, que es expresión y producto de la autonomía privada, el vínculo representativo se genera por un mandato explícito, y por tanto es más estrecho, de modo que pueden determinarse con mayor precisión las obligaciones del representante y su obediencia resulta más directamente controlable por parte del representado. En cambio, en la representación necesaria, y más aún en la orgánica, las obligaciones del representante y las expectativas del representado son, a falta de mandato, inevitablemente más vagas, de modo que los controles de su cumplimiento son más indirectos y genéricos (FERRAJOLI, 2007, vol. I, pp. 374-375).

FERRAJOLI señala que, dado que sólo las personas naturales tienen capacidad de actuar, sólo ellas pueden actuar como representantes. Eso no obsta a que también a una persona jurídica pueda conferírsele el poder de actuar por cuenta de un representado; aunque hemos de ser conscientes de que, en tal caso, decir que el «representante» es la persona jurídica es una forma elíptica de hablar. Nos encontraríamos aquí con una doble relación representativa: por un lado, entre el representado y la persona jurídica representante y, por otro lado, entre ésta y la persona física de su representante o funcionario, relación que sería del tipo que llama «representación orgánica». El problema de la representación orgánica se complica, por tanto, por el hecho de que tal relación 
suele transcurrir no sólo entre la persona física del representante o funcionario y la persona jurídica, sino también entre el propio representante y un determinado órgano de la persona jurídica. Así, por ejemplo, en el caso de una sociedad por acciones, una decisión tomada por su consejo de administración o asamblea de socios sería imputable tanto a la sociedad como a dichos órganos, y lo mismo se podría decir de los órganos del Estado. Tenemos, por tanto, una relación triádica: entre el representante, que siempre está formado por una o más personas físicas, la persona jurídica y su órgano. La relación entre la persona jurídica y sus órganos puede ser llamada «relación orgánica», pero hay que ser conscientes —añade FERRAJOLI— de que tal relación no tiene nada que ver con la de representación orgánica, que sería la representación que llevan a cabo las personas naturales que son sus funcionarios, en ejercicio de las funciones de una persona jurídica o de su órgano. Los órganos y las personas jurídicas a las cuales pertenecen no tienen una relación de representación: los órganos no son representantes ni viceversa ${ }^{16}$ (unos son personas físicas y otros, jurídicas). Un órgano sería para FERRAJOLI aquel sujeto jurídico instituido por un acto tal que todo lo que le es imputado lo es también a la persona artificial a la que pertenece. Por eso tampoco tiene sentido articular la relación entre una persona artificial y las personas naturales de sus funcionarios como una relación orgánica, como si fueran órganos de aquélla. Esta relación sería, por el contrario, una relación de representación necesaria, a la que se llama «orgánica» simplemente por la naturaleza de órganos de los sujetos representados (FERRAJOLI, 2007, vol. I, pp. 376 y 613).

No todas las relaciones que en este contexto de las personas artificiales se dan son, para FERRAJOLI, de tipo representativo. Así, por ejemplo, no sería una relación de representación, en el sentido jurídico definido, la relación entre una persona artificial y las personas naturales que la han constituido: el Estado no representa a la sociedad civil, del mismo modo que una sociedad por acciones no representa a los socios que la han fundado, y tampoco sería, en su opinión, una relación de representación, en el sentido jurídico del término, la considerada «representación política» instituida a través de las elecciones. En este caso se trata — dice FERRAJOLI— de relaciones entre sujetos constituyentes y sujetos constituidos (entre electorado y representantes políticos); relaciones que son en parte jurídicas, en parte sociales y políticas, entre las expectativas de los primeros, que expresan lo que sería, en terminología de FERRAJOLI, el «punto de vista externo» a las instituciones constituidas, y los correspondientes deberes atribuidos a los segundos a través de su acto constitutivo (FERRAJOLI, 2007, vol. I, p. 377). Por tanto, mientras que, como hemos visto, la representación jurídica designa la relación jurídica entre dos sujetos, de los cuales uno actúa en nombre del otro, de modo que los actos del representante son imputados al representado; la representación política designa en cambio la relación que los representantes tienen con sus electores y es una

16 KELSEN, sin embargo, parece aproximar ambas relaciones: «Representación legal y organicidad son conceptos emparentados. Un determinado individuo es considerado órgano de una comunidad, en tanto la situación es vista como si la función que efectivamente el individuo desempeña la desempeñara la comunidad. Determinado individuo es visto como representante del incapaz de hecho en cuanto se interpreta la situación que se presenta como si fuera el incapaz de hecho el que, no de por sí, pero a través de aquel individuo cumpliera sus obligaciones (...). Esta forma de exponer la situación, mediante la cual se expresa la representación legal, reposa, igualmente que la explicación en el caso del órgano, en una ficción: la ficción de la atribución» (KELSEN, 1993, p. 172). 
relación puramente política, de la cual se excluye todo «vínculo de mandato» ${ }^{17}$. Este tipo de representación es, entonces, definido por FERRAJOLI como sigue:

«Representación política es la norma de competencia en razón de la cual la representación orgánica de cara a las funciones públicas es confiada a sujetos elegidos a través del derecho político del voto» (FERRAJOLI, 2007, vol. I, p. 863).

Como hemos visto, no hay pues, para FERRAJOLI, relación representativa de tipo jurídico entre electores y elegidos. La única representación jurídica que se daría en este ámbito sería la relación de representación orgánica que se establece entre los que han sido elegidos a través del derecho político del voto y la persona jurídica del Estado, o su órgano, o alguna otra institución política, a la cual se imputan los actos de aquéllos. La representación política no sería entonces más que una convención, un principium iuris más idóneo que cualquier otro, que se basa en el sufragio universal para seleccionar a los sujetos encargados de las funciones de gobierno. A diferencia de lo que ocurre en la representación jurídica, en la que los actos del representante son imputados también al representado (que es titular de todas las situaciones actuadas por el representante y que es el dominus de la relación), en la representación política no se determina ninguna doble imputación, sino sólo un vínculo genérico de tutela y satisfacción de los intereses representados, que resulta, por un lado, del pactum associationis establecido en la constitución y, por otro lado, del carácter general de los intereses y de las expectativas que las funciones públicas deben tutelar (FERRAJOLI, 2007, vol. II, pp. 167-168).

Lo que la representación jurídica y la política tendrían en común, según FERRAJOLI, sería la exclusión del conflicto de intereses entre representante y representado (FERRAJOLI, 2007, vol. I, p. 374). La representación jurídica —como vimos en su definición- sería la única relación jurídica en la que no sólo no media, sino que se excluye el conflicto de intereses, incluso el virtual ${ }^{18}$. Esta exclusión, que está explícita en la definición de representación jurídica, está implícita también en el carácter público de las funciones ejercitadas por los representantes políticos. Estas funciones se atienen precisamente a la esfera pública, es decir, al interés general, de modo que se excluye toda subordinación a los intereses privados. Obviamente — dice- el voto refleja la opinión y puede que los intereses de cada votante, pero al mismo tiempo considera que justamente por ello el representante político no puede estar vinculado a ellos, sino que es llamado a representar los intereses de todos.

\section{UNA PROPUESTA DE RECONSTRUCCIÓN}

Mi objetivo ahora es intentar presentar una reconstrucción conceptual del fenómeno de la representación en el Derecho, sirviéndome (aunque de manera un tanto libre) de los distintos análisis que acabo de exponer; pues me parece que todos ellos

17 Resulta curioso que FERRAJOLI utilice precisamente el elemento del mandato para contraponer la representación jurídica a la política, cuando él mismo, tal y como acabamos de ver, es consciente de que no en todos los casos de representación jurídica puede hablarse de este «vínculo de mandato».

18 Podríamos considerar, sin embargo, que no en todos los casos de representación se exige esta exclusión del conflicto de intereses (pensemos en algunos casos de representación en el ámbito mercantil), aunque lo que sí parece ser cierto es que el conflicto de intereses genera siempre un problema en la relación representativa que exige al menos una regulación de la misma, es decir una gestión del posible conflicto de intereses. 
ponen de manifiesto algún rasgo interesante de la representación. Para ello adoptaré como punto de partida una perspectiva estructural, de forma que la representación es vista fundamentalmente como una relación. Me ocuparé por tanto, en primer lugar, de analizar los elementos y las características que configuran dicha relación, para a partir de ahí establecer algunas distinciones conceptuales a propósito de la representación que pueden resultar relevantes en el ámbito jurídico.

\subsection{La representación como concepto relacional}

Como acabo de señalar, desde la perspectiva estructural, la representación se presenta como un concepto relacional ${ }^{19}$. Tendríamos entonces dos elementos fundamentales: el representante y el representado, entre los cuales se establece la relación de representación. Pero conviene señalar también la presencia de un tercer elemento: el ámbito de la representación, es decir, el ámbito en el que los efectos de la representación son válidos ${ }^{20}$. La relación de representación podría, entonces, esquematizarse del siguiente modo: «X representa a $Y$, en $Z$ ». En un concepto relacional de este tipo podemos distinguir, por tanto, los siguientes elementos:

1. X: El objeto/sujeto que representa: la representación o el agente representante.

2. $Y:$ El objeto/sujeto que es representado.

3. Z: El ámbito de la representación.

En principio, tanto $X$ (representante) como $Y$ (representado) pueden ser bien sujetos (individuales o colectivos) bien objetos. Podemos pensar en el caso más simple en el que tanto $X$ como $Y$ son sujetos individuales, como por ejemplo cuando el Código Civil establece que «el tutor representa al menor» (art. 267). Pero también es posible que alguno de estos elementos sea una pluralidad de individuos, bien como un mero agregado de individuos, o bien como individuos organizados de alguna manera (una institución o una persona jurídica). Pensemos por ejemplo en la atribución al Rey de la más alta representación del Estado en las relaciones internacionales (art. $56 \mathrm{CE}$ ), o a la atribución a las Cortes Generales de la representación del pueblo español» (art. 66 $\mathrm{CE}$ ). Pero en ocasiones hablamos también, más que de representación de sujetos, de sus intereses (de un individuo o de un grupo o clase de individuos), así por ejemplo consideramos que los sindicatos representan los intereses de los trabajadores. Y podemos encontrarnos también con casos algo más atípicos en los que el representante o el representado no sería un sujeto, sino un objeto, así, por ejemplo, cuando decimos que «la bandera representa a la nación» o cuando se habla de «títulos representativos» de, por ejemplo, préstamos hipotecarios.

19 Este carácter relacional es mencionado, de manera más o menos expresa, por la mayoría de los autores que se han ocupado de caracterizar este concepto. La representación designaría, se dice, una relación social más que un atributo individual, de modo que podría ser conceptualizada como una «propiedad sistémica» (EULAU y KARPS, 1983, p. 299).

20 Para Diggs el representante siempre sería un intermediario entre el principal (o representado) y alguien, un tercero; de modo que podríamos decir que la representación tiene siempre un destinatario. En este sentido, dice este autor, la representación no sólo sería de alguien, sino que estaría dirigida a alguien, o al menos estaría orientada a un ámbito (1968, p. 36). Pero creo que, como señala LEIBHOLZ, el concepto de representación no implica necesariamente la idea de un «destinatario» (entendido como una unidad personal concretamente perceptible), aunque sí estaría orientada a un ámbito (LEIBHOLZ, 1989, pp. 81 y 83 ). 
Pero algo que en todo caso parece excluir la relación representativa es la coincidencia, o identidad, entre representante y representado ${ }^{21}$. La incompatibilidad entre la relación de representación y la de identidad ha sido señalada por diversos autores; así, por ejemplo, éste es el argumento que utiliza M. WEBER para considerar que las relaciones de representación deben diferenciarse de las situaciones de solidaridad, que se fundan sobre la idea de la identidad. Tanto representación como solidaridad serían mecanismos para atribuir responsabilidad o consecuencias por acciones de otro, pero mientras que la situación objetiva de la solidaridad se basa esencialmente sobre la idea de la unidad de un grupo, que viene legitimada y vinculada por la acción de todos sus componentes, y en la que toda acción de cada uno de los partícipes se imputa a todos los demás, la representación se da cuando la acción de un partícipe determinado se imputa a los demás, y esto exigiría que el miembro individual del grupo deja de ser visto exclusivamente como una parte del grupo ${ }^{22}$.

El tercer elemento, $Z$, haría referencia como hemos dicho al ámbito de la representación. Conviene percatarse de que la relación de representación puede -y suele- estar limitada, en el sentido de que sus efectos sólo son válidos bien frente a unos determinados sujetos (que serían, por así decirlo, los destinatarios de la relación representativa) o bien en un determinado ámbito. Así, por ejemplo, la representación que ejercen los procuradores es únicamente válida ante los tribunales (y, en ocasiones, para una concreta actuación judicial), la representación que desempeñan los sindicatos de los trabajadores es válida en el ámbito de la negociación colectiva, los embajadores ostentan la representación de un país en el ámbito diplomático, etcétera.

Determinar el significado de lo que podríamos llamar el «vínculo representativo» sería equivalente a precisar el significado de la expresión «representa a» en el esquema de la relación representativa antes señalado. En los análisis anteriores vimos que se han propuesto diversas «traducciones» de esta expresión; así, y por señalar algunas de las propuestas, la expresión «X representa a $Y$ en el ámbito $Z »$ podría ser sustituida —se dice- en todos o en algunos casos por una o varias de las siguientes expresiones:

- «X cuenta como $Y$ en el ámbito $Z »$.

- «X simboliza a $Y$ en el ámbito $Z »$.

- «X sustituye a $Y$ en el ámbito $Z »$.

- «X actúa por $Y$ en el ámbito $Z »$.

- «X obliga a $Y$ en el ámbito $Z »$.

— «X vela por los intereses de Y en el ámbito Z».

Pero es fácil percatarse de que ninguna de estas traducciones nos sirve para aclarar convenientemente el significado de en qué consiste la relación representativa. En este

21 Podríamos pensar que existen algunos casos de representación en los que sí se daría esta coincidencia; así, por ejemplo, el Derecho español exceptúa en algunos casos la exigencia de procurador y permite que alguien se «represente» a sí mismo ante los tribunales. A pesar de ello, creo que en estas ocasiones se trata de un uso derivado y no central del término «representación», pues en estos casos lo que se quiere hacer presente sí lo está en sentido literal, aunque quizás todavía tenga sentido decir que dicho sujeto se «representa» a sí mismo para remarcar que en estos casos se exceptúa la necesidad de representante.

${ }_{22}$ Cfr. WEBER, 1993, pp. 37-38. En este sentido, y siguiendo a WeBER, LEIBHOLZ señala que la duplicidad exigida por la representación (refiriéndose al ámbito de la política) sólo aparece cuando, a partir del proceso de racionalización y diferenciación, el individuo se contrapone, como entidad autónoma y autojustificante, a la comunidad solidaria y unitaria (LEIBHOLZ, 1989, p. 71). 
punto creo que puede resultar útil el análisis de A. Ross de los conceptos $t \hat{u}-t \hat{u}$, para darnos cuenta de que para explicar con mayor precisión en qué consiste este nexo o vínculo tenemos que acudir, bien a lo que justifica o crea dicha relación (a su antecedente: el «título» que justifica considerar a $X$ como representante de $Y$ en el ámbito $Z$ ), bien a las consecuencias que la misma produce (al consecuente), y que la relación de representación no es ninguna cosa mágica que se sitúa en medio, sino más bien una técnica de presentación, que sirve $\mathrm{a}-\mathrm{y}$ es necesaria para- fines sistemáticos ${ }^{23}$. Pues bien, creo que no se puede decir mucho más a propósito de en qué consiste la representación si pretendemos cubrir todos los supuestos en que empleamos este término, o sus derivados, en los ámbitos relacionados con el Derecho. Si queremos concretar algo más necesitamos descender a los diferentes supuestos.

\subsection{Representatividad, representación simbólica y representación práctica}

Como vimos al principio, en el ámbito jurídico encontramos casos muy heterogéneos en los que consideramos que existe una relación de representación. Sin embargo creo que todos ellos (o al menos, la gran mayoría) pueden reconducirse a tres categorías, que implicarían sentidos distintos de representación, y que a continuación voy a intentar caracterizar.

Tomaré como punto de partida el análisis que realizaba DigGS (1968) y que le llevaba a distinguir entre dos sentidos de representación: uno descriptivo, pictórico o simbólico y otro práctico. O, en la terminología de LAPORTA (1989), entre una representación descriptiva (en la que el representante representa porque es algo: un símbolo o reflejo) y una representación normativa (en la que el representante representa porque tiene competencia o poder para hacer algo, o porque debe hacer algo). Tendríamos entonces dos sentidos de representación: el primero haría referencia a una dimensión podríamos decir de reproducción, en el que representar sería más bien estar por o en lugar de; el segundo haría referencia a una dimensión de acción, y en él, representar significaría actuar por o en lugar de ${ }^{24}$. A este último le denominaré «representación práctica» y de momento me referiré al primero simplemente como «representación no práctica» ${ }^{25}$.

En el caso de la representación «no práctica», el elemento $X$ de la relación representativa (y al que - como señalaba DigGS - no siempre llamamos «representante», sino en algunos casos «la representación») lo que hace es, en algún sentido, aludir (describir, reflejar, simbolizar) al representado $(Y)$, que a su vez es visto como algo a describir o contemplar. Sin embargo, en el caso de la representación «práctica» el

23 Cfr. Ross, 1976, pp. 41-42.

${ }^{24}$ Cfr. CotTA, 1983, p. 1426.

25 Estos dos sentidos de «representación» se corresponderían, en italiano, con dos términos distintos: «rappresentazione» (que coincidiría con la representación no práctica: descriptiva, simbólica, pictórica...) y «rappresentanza» (que vendría a coincidir con la representación práctica), de manera que en esa lengua no se plantea la ambigüedad aquí señalada (y que sí se da con el término español, y también, por ejemplo, con el término inglés «representation» o con el francés «représentation»). Sin embargo, la ambigüedad resurge en italiano cuando se trata del verbo «rappresentare» o del adjetivo «rappresentativo». Cfr. BOBBIO, 1999, esp. pp. 414-417. 
agente que actúa como representante $(X)$ literalmente tiene que actuar por o en lugar del representado $(Y)$, quien es por tanto visto no como algo a describir o contemplar, sino como portador de intereses, es decir, como sujeto activo (y, por tanto, también como agente, aunque en un sentido distinto al que consideramos agente al representante). De aquí se seguiría que, mientras que en el caso de la representación «no práctica» tanto el elemento $X$ como el elemento $Y$ de la relación representativa podrían ser o bien sujetos o bien objetos, en el caso de la representación «práctica» el elemento $X$ (el representante) tiene que ser un agente, en el sentido de que ha de ser un sujeto con capacidad para actuar por sí mismo, y el elemento $Y$ (el representado) tiene que ser al menos un sujeto capaz de ser portador de intereses.

A su vez, dentro de lo que hemos considerado como representación «no práctica», es usual distinguir dos supuestos que presentan bastantes diferencias entre sí y que coincidirían con dos de las dimensiones de la representación que señalaba PITKIN: la representación como correspondencia, descripción o reflejo $(R 3$, a la que llama «representación descriptiva») y la representación como identificación simbólica (R4). En el primer caso, podríamos decir que la relación de representación se fundamenta en una semejanza o correspondencia de características entre los elementos $X$ e $Y$ de la relación representativa (sería la idea que está detrás de considerar que el Parlamento representa a la nación porque es su reflejo o su reproducción a escala), o bien también en algún otro tipo de conexión «natural» distinta a la de la semejanza ${ }^{26}$ (por ejemplo, si consideramos que un individuo representa - o refleja - a un grupo por ser miembro del mismo). En el segundo caso, sin embargo, no se exige la semejanza (o algún otro tipo de conexión natural) entre el elemento $X$, que operaría como símbolo, y el elemento $Y$, lo representado o simbolizado. Aquí, el vínculo se basaría en un complejo proceso intelectivo-sensorial que hace que el elemento $X$ sea capaz de evocar a $Y$. Contraponiéndolo al caso anterior, en el que el vínculo representativo se basaba en relaciones de semejanza, o en un sentido más amplio, de algún tipo de conexión natural, aquí se trataría de una relación puramente convencional ${ }^{27}$.

Cuando hablamos de la representación en el Derecho solemos tener en mente lo que aquí he denominado representación «práctica». Sin embargo también encontramos que en algunas ocasiones nuestros sistemas jurídicos establecen o toman en consideración relaciones de representación «no práctica». Me refiero: 1) a supuestos en que se toma en consideración una relación de representación del tipo $R 3$ (lo que PITKIN denomina representación «descriptiva») para reconocer —o negar- el carácter representativo o la representatividad a un determinado sujeto, órgano, asociación, etc., y 2) a supuestos de representación simbólica $(R 4)$ establecidos por el Derecho (como cuando, por ejemplo, decimos que la bandera representa a la nación o que el rey representa

26 Pensemos, por ejemplo, en los diversos tipos de metonimias: la parte por el todo; el continente por el contenido; el origen por el producto; etc. En todas ellas la relación que existe no es exactamente de semejanza pero podríamos decir que existe algún tipo de conexión «natural», como contrapuesta a «arbitraria» (en el sentido de que la relación con el objeto se basa exclusivamente en una convención).

27 PITKIN consideraba que la conexión simbólica era, en algún sentido, arbitraria, dado que la misma sólo existe si se cree en ella (PITKIN, 1985, p. 109). En esta misma dirección, PERELman habla de la relación de «participación» que parece existir entre un símbolo y lo que éste evoca, considerando que se trata de una relación de «naturaleza casi mágica, en todo caso irracional»; lo que tiene de peculiar (e impresionante) el enlace simbólico — dice PERELMAN- es que el símbolo y lo simbolizado se integran en una realidad mítica o especulativa en la cual participan recíprocamente (PERELMAN, 1989, p. 509). 
al Estado). Me ocuparé ahora brevemente de estos dos sentidos de representación, a los que llamaré, respectivamente, «representatividad» y «representación simbólica»; y avanzaré algunas de las relaciones que pueden surgir entre ellos y la «representación práctica» (a la que dedicaré el resto del trabajo).

Como hemos visto, la naturaleza de la conexión de la relación representativa es distinta en los casos de representación simbólica y los que están detrás del reconocimiento de representatividad. A partir de ahí es fácil darse cuenta de que, en cada uno de estos supuestos, el vínculo representativo se origina en sistemas de referencia distintos. En el caso de la representación simbólica que, por ejemplo, atribuimos al rey o a la bandera del Estado o de la nación, lo que origina el vínculo, el «título» que justifica que se considere que algo o alguien representa, tiene que encontrarse establecido en, o reconocido por, el Derecho; la relación de representación es en este sentido constituida por el Derecho (serán las normas jurídicas las que establezcan la relación convencional entre $X$ e $Y$ ). Sin embargo, la representatividad presupone una relación originada, en algún sentido, fuera del sistema jurídico (aunque como veremos no de manera totalmente independiente a los valores reconocidos por el mismo). No consideramos que $X$ tiene «representatividad» o es «representativo» de $Y$ porque una norma jurídica así lo establece, y es precisamente por ello por lo que podemos usar este concepto como una especie de ideal regulativo que nos sirve para valorar algunas instituciones. Hemos visto que a veces se califica a la representación que está detrás del reconocimiento de la representatividad como «descriptiva», pero hay que ser conscientes de que esta terminología puede resultar engañosa, porque parecería dar a entender que hace referencia a una mera cuestión de hecho, ajena a cuestiones valorativas. Sin embargo, afirmar o negar la representatividad de un órgano por considerarlo, por ejemplo, como «fiel reflejo» de una determinada realidad implica haber elegido algunas propiedades como relevantes, como aquéllas que han de ser reflejadas (puede ser el sexo o la raza o el estatus o el origen territorial o la diversidad...), y esta selección estará basada en evaluaciones, que serán realizadas a la luz del particular sistema de referencia en el que se quiera hacer valer la relación representativa. Del mismo modo, cuando la representatividad no se basa en la idea de «semejanza», sino en otro tipo de conexión («ser un miembro de», «ser elegido por»...), también son necesarias evaluaciones para determinar qué tipo de conexión es la adecuada (en algunos casos consideramos representativo a quien ha sido elegido por sorteo, mientras que en otras ocasiones puede parecernos indispensable para ostentar representatividad el ser elegido por votación). Calificar esta conexión como «descriptiva» puede, por tanto, inducir a engaño por ocultar precisamente esos juicios valorativos implícitos.

Conviene ser conscientes de que, pese a que a efectos analíticos podamos distinguir los supuestos de representación práctica de los de representación no práctica (en sus dos modalidades de representatividad y representación simbólica), los mismos pueden interrelacionarse y de hecho es usual que en determinados ámbitos se presenten conjuntamente. Por lo que respecta a la representación simbólica, cuando ésta recae en un sujeto, y no en un objeto, la misma puede, y suele, darse conjuntamente con la representación práctica ${ }^{28}$. Pensemos por ejemplo en la representación que ostenta el

${ }_{28} \mathrm{Y}$ cuando esto no ocurre, como por ejemplo pasa en España con la representación que ostenta el rey, solemos hablar de una representación «puramente» simbólica precisamente para recalcar la falta del aspecto práctico de la representación (el rey no actúa por el Estado). 
rector de una universidad respecto de la misma; en este caso puede considerarse que el rector simboliza a la universidad (y, así por ejemplo, si el rector está presente en un acto, consideramos que la universidad estaba en algún sentido presente), y también que el rector actúa por la universidad; de modo que en esos casos podrían considerarse como dos aspectos de una misma relación de representación.

También encontramos relaciones entre la representatividad y la representación práctica. En este sentido, por ejemplo, cuando se afirma que el Parlamento representa al país se suele hacer en el doble sentido de que actúa en nombre y por cuenta de los electores, y en el sentido de que lo refleja o reproduce ${ }^{29}$. Pero, como hemos apuntado, esta última conexión tiene más bien un aspecto prescriptivo: no se trata tanto de que aquí quien actúa por otros (es decir el que los representa en sentido práctico) de hecho también los representa en el sentido de que ostenta representatividad respecto a los mismos, sino más bien que lo debería hacer, para lo cual debería cumplir con ciertos requisitos. En el ámbito político, la representatividad (como opuesta a la idea de exclusión política) opera así como una especie de ideal regulativo, que legitimaría algunos casos de representación práctica (aquéllos en los que el representante posee ciertos requisitos o ha sido instituido de determinada forma). Esta conexión entre representación práctica y representatividad en el ámbito político podría ayudar a explicar por qué en muchos casos la expresión «representación política» se utiliza como prácticamente sinónima de «democracia»; esto ocurre cuando en el concepto de representación que se maneja en el ámbito político se incorpora tanto la idea de representación práctica (alguien actúa por otro u otros) como la exigencia de que el representante tenga «representatividad» (es decir, esté «legitimado» para ocupar dicho cargo). Así, por ejemplo, tal y como vimos, FERRAJOLI incorpora a su definición de representación política la exigencia de que el representante sea elegido democráticamente. Sin embargo, no todos los autores que se han ocupado de la representación política operan de este modo; KELSEN, por el contrario, remarca la idea de que tan representación política (en sentido - diríamos nosotros- exclusivamente práctico) es la que ostenta un presidente electo como un monarca ${ }^{30}$.

\subsection{Tipos de representación práctica: la representación individual, la representación institucional y la representación colectiva}

Centrémonos ahora en los casos de representación práctica que encontramos en el Derecho; como hemos apuntado antes, aquí tanto el elemento $X$ como el $Y$ de la relación representativa han de ser sujetos y no meros objetos: el representante $(X)$, en tanto que literalmente ha de actuar por el representado, habrá de tener necesariamente la capacidad efectiva para actuar, capacidad que sólo tienen los seres humanos, por lo que

${ }^{29}$ Cfr. BobBio, 1999, p. 414. Tal como recogimos en los análisis anteriores, esta conexión sería también señalada, por ejemplo, por DigGS o SARTORI, quienes sostienen que una adecuada comprensión de lo que se considera como representación política exige tener en mente el sentido de representación como reflejo.

30 En este sentido, dice KELSEN, tan «representación política» es la que lleva a cabo una sola persona por razón de su nacimiento que la que llevan a cabo los que han resultado elegidos en un proceso democrático; lo único que se necesita es que las actuaciones del representante se hagan en interés del representado (cfr. KELSEN, 1993, pp. 302-305). 
sólo estos podrán ser representantes ${ }^{31}$; y el representado $(Y)$ es a su vez visto, no como algo a describir, sino como un sujeto portador de intereses. Pero aquí nos encontramos con que el representado puede ser un sujeto de muy diversa naturaleza y creo que, dependiendo precisamente de ante qué tipo de sujeto representado nos encontremos, podemos distinguir diversos tipos de representación. En particular creo que podemos encontrar en el Derecho al menos tres tipos distintos de representación atendiendo a este criterio: el de personas físicas consideradas individualmente, el de «construcciones jurídicas» (es decir personas artificiales o jurídicas o instituciones u órganos) y el de «sujetos colectivos» (conjunto de personas consideradas colectivamente).

3.3.1. El caso más simple de representación que podemos encontrar sería, quizás, aquel en el que el sujeto representado, el elemento $Y$ de la relación representativa, es una persona física, un ser humano individual, o más de uno pero considerados individualmente. En estos casos podemos hablar de «representación individual». Tanto el elemento $X$ (el representante) como el elemento $Y$ (el representado) de la relación hacen referencia a un sujeto o a un conjunto de seres humanos (en este último caso considerados individualmente, como un mero agregado de sujetos) y que son independientes entre sí, en el sentido de que su existencia no depende de la propia relación de representación. Este tipo de representación se da fundamentalmente en lo que se considera como el ámbito del Derecho privado (aunque no exclusivamente), dado que los sujetos representados son aquí individuos particulares en tanto tales, por lo que algunos se refieren a este tipo de representación como «representación privada» ${ }^{32}$.

A su vez, dentro de esta representación individual suelen distinguirse dos supuestos dependiendo de que el individuo representado tenga o no capacidad de actuar por sí mismo en un determinado ámbito según el sistema de referencia (en este caso, el Derecho). En el primer supuesto nos encontraríamos con lo que en el ámbito de la dogmática civil suele llamarse representación voluntaria (o consensual, o negocial). En el segundo caso podemos hablar de «representación necesaria»; a veces, también se la llama «legal», haciendo referencia a que es constituida directamente por la ley y no por un negocio jurídico, pero hay supuestos en los que la representación puede estar constituida no directamente por la ley sino por sentencia judicial, o incluso casos en los que se obliga a alguien a actuar a través de representante, y en ese sentido se trataría de una representación «necesaria», pero al mismo tiempo se exige un acto de apoderamiento del representado para constituir la relación representativa (como ocurre en el ámbito procesal).

En el caso de la representación necesaria, por tanto, el representado no puede actuar por sí mismo según el sistema de referencia, en nuestro caso el Derecho (bien por ser un menor, bien por estar incapacitado para actuar, en general, o para el concreto acto de que se trate, bien por estar ausente, etc.) y por tanto necesita de alguien que pueda actuar en su nombre y cuidar de sus intereses. Sin embargo, en el supuesto de la representación voluntaria, el sujeto representado $(Y)$ sí puede actuar pero, en uso

31 Aunque hay ocasiones, como señalaba FERRAJOLI, en las que se establece un doble vínculo y por tanto en algún caso el representante puede ser un órgano, que a su vez actuará a través de un representante que, en último término, tendrá siempre que ser una persona natural.

32 Esta terminología es de uso más común entre los juristas. Pero, dado que la contraposición entre Derecho público y privado no es especialmente clara, prefiero la terminología de representación «individual». 
de la autonomía de su voluntad, decide apoderar a otro $(X)$ para que le represente en un determinado ámbito $(Z)$. Y será precisamente a través del apoderamiento donde se precise el ámbito de la representación (para una determinada acción, o para una clase de acciones; por un determinado tiempo, o indefinidamente hasta que sea revocado; ante un destinatario concreto, o erga omnes...). Hay una cuestión relevante que distingue ambos supuestos: en un caso el sujeto tiene voluntad, y la representación surge precisamente como consecuencia del ejercicio de la misma (determinando no sólo quién es representante, sino también en qué ámbito); mientras que en el otro caso, dicha voluntad o no existe en absoluto o no es considerada relevante o suficiente (por ser en algún sentido minusvalorada) por el sistema de referencia (el Derecho).

3.3.2. El segundo supuesto al que me quiero referir sería aquél en el que el sujeto representado, $Y$, no es una persona física (o varias consideradas individualmente), sino una persona artificial o jurídica. Pensemos en los siguientes supuestos: el rector representa a la universidad; el gerente de una sociedad anónima ostenta su representación, etc. En todos estos casos nos encontramos con que forma parte de las propias reglas que constituyen la institución de que se trate (la sociedad anónima, la universidad, la asociación...) el adscribir a determinados sujetos su representación, es decir, la capacidad de actuar en su nombre.

Propongo hablar aquí, siguiendo la terminología utilizada por FERRAJOLI, de «representación institucional» ${ }^{33}$. En todos los supuestos de representación de este tipo el representado es por definición una persona artificial y, por tanto, dado que tales sujetos no pueden actuar por ellos mismos, la representación será siempre necesaria para imputarles acciones; el único modo de «actuar» que tienen estas entidades es precisamente a través de un representante. Conviene también notar que, justamente por eso, aquí no hay, en ningún caso, una voluntad del sujeto representado a la que el representante pueda serle fiel: lo que se representa no son los diferentes individuos que pueden haber creado la persona jurídica, sino ésta misma; y la voluntad que se le imputa a ésta se realiza precisamente a través del entramado de reglas que la constituyen; reglas que presuponen, entre otras cosas, la institución de un representante. Quizás por eso en ocasiones se afirma que este tipo de relación representativa implica, por así decirlo, que el sujeto representado, $Y$, en realidad no existe con anterioridad a la propia relación representativa, sino que más bien sería resultado de la misma ${ }^{34}$. Creo que con ello lo que se quiere decir es que el representado no es independiente de su representante, pues lo necesita para existir. Esta sería la idea que subyace al famoso - al mismo tiempo que muy discutido- pasaje de HOBBES a propósito de la representación política: «Una multitud de hombres se convierte en una persona cuando está representada por un hombre o por una persona (...). Es, en efecto, la unidad del representante, y no la unidad de los representados, la que hace la persona una» ${ }^{35}$. Y en un sentido parecido,

33 FERRAJOLI considera que también se podría hablar aquí de «representación orgánica», para indicar que, en su opinión, a quien se representa en estos casos es tanto a la persona jurídica, como a los órganos de la misma. Pero el término «representación orgánica» se ha utilizado también en un sentido distinto, para referirse a la representación de los intereses de una determinada clase o estatus social como contrapuesta a la representación de los ciudadanos en cuanto tales (vid., por ejemplo, BовBIO, 1994, p. 55).

34 Vid., en este sentido, CRIADO DE DIEGO (2007).

35 HobBes, 1980, p. 135. La cursiva es del autor. Pueden verse comentarios a esta cita, por ejemplo, en Brunet, 2004, p. 52, y GarRorena Morales, 1991, p. 26. 
también KELSEN señala que «la atribución de una función determinada por un orden normativo y cumplida por un individuo a la comunidad constituida por ese orden, implica la personificación de esa comunidad» ${ }^{36}$.

3.3.3. Hay, por último, una tercera modalidad de representación relevante para el Derecho, en la que el elemento $Y$ de la relación representativa no viene constituido por un sujeto individual, sea natural o artificial, sino por un grupo o colectivo de individuos, pero no como un mero agregado de sujetos considerados individualmente, sino como un grupo conformado por todos aquellos que comparten algún rasgo o característica, lo que hace presuponer que comparten intereses en cuanto poseedores de dicha característica (bien sean trabajadores, estudiantes, consumidores y usuarios, etc.).

Podríamos pensar que la relación que se da en este tipo de representación es equivalente a la que vimos en el caso de la representación individual, con la única peculiaridad de que uno de los elementos de la relación, el representado, está constituido por muchos individuos; pero conviene darse cuenta de que aquí no se pretende representar a cada uno de los individuos que conforman el colectivo, sino únicamente a un aspecto de los mismos que se supone es compartido por todos ellos. Cada individuo tiene una multitud de intereses y este tipo de representación no trata de tomarlos en cuenta a todos, sino exclusivamente a aquéllos que son los que se supone que poseen los individuos en cuanto que miembros de la clase que conforma el sujeto representado. Así, por ejemplo, cuando se atribuye la representación de los trabajadores a los sindicatos, no se espera que éstos representen a cada uno de ellos en cuanto sujetos individuales con una diversidad heterogénea de intereses, sino precisamente los intereses que se supone comparten «en cuanto» trabajadores. Y lo mismo ocurriría con las «asociaciones de consumidores y usuarios» que han de representar los intereses de los consumidores y usuarios (sean o no sus asociados). Para referirme a este tipo de representación utilizaré la expresión «representación colectiva» ${ }^{37}$.

Pues bien, en mi opinión, lo que se suele considerar como representación política pertenecería a este tipo de representación. Obviamente excede de las posibilidades de este trabajo ofrecer una caracterización de este tipo de representación, pero sí quiero apuntar algunas ideas a partir de lo visto hasta ahora y utilizando como hilo conductor el análisis de Bоввіо. Para este autor, el debate sobre la representación en el ámbito político está dominado por la controversia en torno a dos cuestiones: 1) los poderes del representante, es decir, ¿cómo representa $X$ a $Y$ ?, y 2) el contenido de la representación, es decir, ¿qué cosa representa $X$ ? que sería la cuestión de la que aquí nos estábamos ocupando. Y para ella, dice BoBBio, pueden encontrarse dos respuestas: $X$ representa a $Y$ con respecto a sus intereses generales como ciudadano o bien respecto a sus intereses particulares, por ejemplo, como obrero, como comerciante, etc. Esta

36 KelSEN, 1993, p. 161. Conviene notar que KeLSEN considera a ese individuo como órgano jurídico, pero - como antes vimos- entiende que la relación de «organicidad» y la de «representación» están emparentadas (cfr. KELSEN, 1993, p. 172).

37 Quizás también podría llamársele «representación de intereses», pero prefiero no utilizar esta terminología, porque parece dar a entender que en los otros tipos de representación no hay intereses en juego. Sin embargo, creo que en todos los supuestos de representación práctica los intereses de los representados juegan un papel preponderante (incluso en la individual, aunque aquí serían los intereses de un solo individuo). En todo caso, y siguiendo a BURKE, podría hablarse de representación de «intereses desvinculados» o impersonales: no se trataría tanto del interés de los granjeros, sino del interés agrícola (cfr. PITKIN, 1985, cap. 8). 
diferencia en cuanto a la respuesta sobre qué cosa se representa (si intereses generales o particulares) repercute también, señala BOBBIO, en la cuestión acerca de quién debe representar (quién está legitimado para ello). Si el representante es llamado a representar los intereses generales del representado, no es necesario que pertenezca a su misma profesión; en cambio, cuando es llamado a representar los intereses específicos de una cierta rama de actividad, pertenecerá normalmente a la misma profesión de los representados, a este tipo de representación se le suele llamar por tanto «representación orgánica» (BоBBiO, 1994, p. 54).

Ahora bien, entre las dos cuestiones antes distinguidas (¿cómo representar? y ¿qué cosa se representa?), existiría, en opinión de BoBBIO, una cierta relación. Hay dos modos en que puede responderse a la primera pregunta: $X$ puede representar a $Y$ bien como delegado o bien como fiduciario. Si $X$ es un delegado, es simplemente un portavoz, un medio de sus representados y por tanto su mandato es extremadamente limitado y revocable. Si en cambio $X$ es un fiduciario tiene el poder de actuar con cierta libertad en nombre y por cuenta de los representados en cuanto goza de su confianza, y puede interpretar a discreción los intereses de ellos. En este segundo caso se dice que $X$ representa a $Y$ sin obligación de mandato (o en la terminología usual, que no existe mandato imperativo). Pues bien, la figura del representante como delegado se vincula en opinión de BOBBIO con la representación de intereses específicos, mientras que el representante como fiduciario suele ir vinculado con la representación de los intereses generales. $\mathrm{Y}$ de entre estas dos opciones a la hora de dar cuenta de en qué consiste la representación política, como es sabido BOBBIO se decanta por considerar que el representante político debe verse como un fiduciario que ha de velar por los intereses generales ${ }^{38}$, de modo que los representantes se deben distinguir entre sí, no por su oficio, sino por las diversas visiones globales que se forman de los problemas ${ }^{39}$.

\subsection{La representación práctica: aspectos constitutivos y regulativos}

Si utilizamos de nuevo la idea de los conceptos $t \hat{u}-t \hat{u}$, a la hora de analizar el concepto de representación práctica podemos distinguir, por una parte, las cuestiones relativas a su antecedente (es decir, a los diversos modos en que se puede constituir una relación representativa) y, por otra parte, lo relativo a su consecuente (es decir, las consecuencias que se anudan a la existencia de dicha relación).

38 Cfr. BobBIO, 1999. Creo que en un sentido similar LeIBHOLZ (1989, p. 74) sostenía que sólo donde el portador de la idea representativa reivindica para sí un valor específico, una dignidad y una autoridad particular, se puede hablar propiamente de «Repräsentation» (como contrapuesta a «Vertretung», que sería la representación típica del ámbito privado) y así, por ejemplo, considera que se puede hablar de «Repräsentation» de un ciudadano en cuanto tal pero no de un mero individuo (aquí sólo podría hablarse de «Vertretung»).

39 De todos modos, BOBBIO considera que la «representación orgánica» no es en sí misma una aberración, sino que hay situaciones en las que la misma sería deseable e incluso inevitable. Así, por ejemplo, dice que es normal que un consejo técnico que lleve a cabo su función y toma sus decisiones en un campo técnico bien delimitado esté compuesto por profesores de facultad y no por representantes de partidos políticos (BOBBIO, 1994, pp. 58-59). No estoy muy segura, sin embargo, de que en este concreto ejemplo diríamos que los profesores que forman parte de un consejo técnico que ha de tomar decisiones de carácter técnico deban ser considerados «representantes» de los intereses específicos de los profesores. 
Por lo que respecta a lo que he considerado el antecedente, nos encontramos con que el Derecho regula diversos modos de crear (y de extinguir) la relación representativa; las posibilidades son muy diversas dependiendo fundamentalmente del tipo de sujeto que sea representado, y que da lugar a la tipología de representación práctica a la que me he referido en el apartado anterior. Así, y por poner sólo algunos ejemplos, en unas ocasiones (las que se suelen considerar como representación voluntaria o negocial) lo que origina la relación representativa sería la voluntad del representado, a través de un negocio jurídico, en otros casos nos encontramos con que la representación es constituida directamente por una norma jurídica heterónoma (una ley o una sentencia). También hay casos en los que el Derecho establece de manera vinculante el procedimiento para generar una determinada relación representativa, como cuando por ejemplo se establece legalmente que los representantes sean los que resulten elegidos a través de una votación o de un sorteo. Estos casos podrían considerase como intermedios entre un apoderamiento totalmente bajo el control del representado y un apoderamiento establecido heterónomamente por el ordenamiento.

Pero lo que ahora me interesa es lo que se refiere al consecuente: qué consecuencias se siguen del hecho de se haya constituido, por cualquiera de los medios previstos en el Derecho, una relación de representación práctica, de modo que alguien $(X)$ pasa a representar a otro sujeto $(Y)$ en un determinado ámbito $(Z)$. Y creo que conviene percatarse de que en el caso de la representación práctica, el consecuente presenta tanto un aspecto, digamos, constitutivo (los actos de $X$ en el ámbito $Z$ cuentan como actos de $Y$, es decir, las consecuencias de los actos realizados por $X$ en el ámbito $Z$ se imputan a $Y$ ), como también un aspecto regulativo. La consecuencia de que se instituya a alguien como representante de otro sujeto, generando así la relación representativa entre ambos, no es sólo que se producirá a partir de ese momento la imputación de las consecuencias jurídicas de los actos realizados por el representante a la esfera de situaciones jurídicas del representado en el ámbito de validez de la relación representativa, sino también que surgen para el representante unas ciertas obligaciones de actuar de una determinada manera por el hecho precisamente de ocupar ese rol. El aspecto regulativo se ocupa por tanto de determinar en qué consiste la actividad que ha de desarrollar el representante; se trata de la perspectiva o dimensión de la representación que PITKIN consideraba precisamente sustantiva (R5), y que podía ser caracterizada como la actuación en interés de otro. En este sentido creo que no se justifica la contraposición que algunos autores realizan entre dos sentidos de representación: entendida como «actuar por otro», o entendida como «actuar en interés de otro» ${ }^{40}$. Ambas ideas no sólo no son excluyentes sino que se dan conjuntamente. En todos los supuestos que consideramos de representación práctica se da al mismo tiempo una actuación «por otro» (en el sentido de que al representado se le imputan las consecuencias jurídicas de las acciones realizadas por el representante), como una actuación «en interés de otro» (en el sentido de que la actividad del representante debe estar realizada siempre en interés del representado). Se trataría de los dos aspectos, el constitutivo y el regulativo, de la representación práctica.

40 Así, por ejemplo, Wellman, 1997, p. 18. Muchos otros autores, sin embargo, son conscientes de que la representación incorpora estos dos aspectos; en este sentido pueden resultar ilustrativas las definiciones de FERRAJOLI que antes analizamos. 
Centrémonos ahora en el aspecto regulativo. Como he dicho, creo que la relación representativa implica una serie de obligaciones para el representante que pueden describirse como la obligación de actuar «en interés de» quien sea el representado. Y en mi opinión esta caracterización es válida para todos los tipos de representación práctica (tanto la individual, como la institucional o la colectiva). Por supuesto, no es fácil —ni puede ser homogéneo- determinar cómo debe entenderse este «interés» referido a los distintos tipos de sujetos que pueden ser representados: seres humanos autónomos, menores, personas jurídicas, colectivos... De todos modos, creo que considerar —como hacen algunos autores— que el concepto «originario» de representación —el que serviría para explicar, aunque fuera de manera derivada, todos los supuestos de representación - se vincula con la idea de mandato ${ }^{41}$, y por tanto las obligaciones del representante pueden reconducirse a la idea de obediencia a la voluntad del representado es equivocada. Tal y como hemos visto, esta voluntad sólo puede estar presente en algunos casos de representación, no en todos (pues no siempre el representado tiene efectivamente voluntad) y en ellos por supuesto su papel puede ser fundamental (en los casos de representación voluntaria) a la hora de crear o revocar la relación representativa, y de determinar su ámbito de validez (el apoderamiento puede ser simplemente para comprar una finca rústica en una localidad; o para gestionar todos los negocios...), pero incluso en estos casos, dentro de los límites marcados por el apoderamiento, la conducta del representante deberá llevarse a cabo siempre persiguiendo el interés del representado ${ }^{42}$. En este sentido creo que la actividad del representante puede ser caracterizada como «discrecional», en el sentido de que en el margen de maniobra del que normalmente gozará el representante, su actividad estará regulada, además de por reglas de acción que impongan límites a su actuación, por normas de fin que obligan a perseguir el interés del representado. Estas normas no determinan de antemano la concreta acción que se debe realizar, sino más bien el fin a conseguir (en este caso la maximización del interés del representado), y será al destinatario de la norma, en este caso al representante, al que corresponda determinar cuál es la acción más adecuada a emprender en cada caso, siendo el responsable de la decisión adoptada ${ }^{43}$.

Pero tratar a fondo estas cuestiones implicaría desbordar el concepto de representación para adentrarnos en el de responsabilidad, en su sentido de deberes asociados al desempeño de un $\mathrm{rol}^{44}$. En este punto conviene notar que una adecuada comprensión de lo que la representación significa en el Derecho exige tomar en cuenta, además de la perspectiva estructural aquí analizada, lo que podríamos considerar como una pers-

${ }^{41} C f r$, por ejemplo, DidiER (2000, p. 5), quien analiza el papel central de la voluntad para la teoría considerada clásica de la representación jurídica.

${ }^{42} \mathrm{Y}$, en todo caso, creo que esta vinculación a la voluntad del representado podría verse como una especificación del supuesto de actuación en interés del representado (en el caso de sujetos autónomos, podemos considerar que sus intereses implican el respeto a su voluntad). E incluso aquí podría llegar a darse el caso de que (tras la ponderación de intereses realizada a la luz de las circunstancias del caso) sea lícito o incluso debido para el representante apartarse de un determinado mandato.

${ }_{43}$ Sobre el concepto de discrecionalidad que estoy aquí empleando, y la caracterización de las normas de fin, vid. LIFANTE VIDAL, 2006.

${ }^{44}$ HART alude a este sentido de responsabilidad en los siguientes términos: «siempre que una persona ocupe un lugar o puesto determinado en una organización social, respecto del cual se le asignan deberes específicos para promover el bienestar o impulsar de manera específica las metas o propósitos de la organización, se puede decir con corrección que esta persona es responsable del cumplimiento de estos deberes o de hacer lo necesario para satisfacerlos» (HART, 1968, p. 212, la traducción es mía). 
pectiva funcional, que se ocuparía de determinar la función (o, mejor dicho, funciones) que desempeña la institución de la representación en los distintos ámbitos del Derecho (en este sentido, es usual encontrar referencias a la representación como una estrategia contra la ausencia o incapacidad de un sujeto, o bien a la división del trabajo, etc.) y, junto a ello, una perspectiva valorativa o justificativa de la actividad del representante y que se ocuparía de proporcionar los fines o valores respecto a los cuales juzgar o bien la configuración de la institución de la representación en un determinado sistema, o bien la concreta actividad desarrollada por un representante.

\section{BIBLIOGRAFÍA}

ACCARINO, B., 1999: Rappresentanza, Bolonia, Il Mulino.

Atienza, M., y Ruiz Manero, J., 1996: Las piezas del Derecho, Barcelona, Ariel, 1996.

Bobiio, N., 1994: El futuro de la democracia, trad. J. F. Fernández SAntillán, México, Fondo de Cultura Económica.

- 1999: «Rappresentanza e interessi», en Teoria Generale della politica, a cura de M. BOVERO, Torino, Einaudi, 1999, pp. 410-428.

BRUneT, P., 2004: Vouloir pour la nation. Le concept de représentation dans la théorie de l'État, Bruylant, Publications de l'Université de Rouen, Paris, LGDJ.

CotTa, M., 1983: Voz «Representación política», en N. BobBio, N. Matteuci y G. Pasquino, Diccionario de política (ed. española: J. ARICO y J. Tula), Madrid, Siglo Veintiuno Editores, pp. 1425-1433.

CRiado de Diego, M., 2007: Representación, Estado y Democracia, Valencia, Tirant lo Blanch.

De la Oliva, A., 2004: Derecho procesal civil. El proceso de declaración, Editorial Universitaria Ramón Areces.

DiDIER, Ph., 2000: De la représentation en droit privé, Paris, Librairie Genérale de Droit et de Jurisprudence.

DíEZ-PICAZO, L., 1979: La representación en el Derecho privado, Madrid, Cívitas.

— 2004: «En torno al concepto jurídico de "representación”», en R. DEL ÁGUILA TejerinA (coord.), La representación en el Derecho, Anuario de la Facultad de Derecho de la Universidad Autónoma de Madrid, 8, pp. 311-316.

Diggs, B. J., 1968: «Practical Representation», en Nomos, X, pp. 28-37.

Eulau, H., y Karps, P. D., 1983: «Le componente della responsività» trad. de A. PAPPALARDO (original inglés de 1977), en La rappresentanza politica, D. Fisichella (coord), Milano, Giuffrè editore, pp. 291-322.

Ferrajoli, L., 2007: Principia Iuris. Teoria del diritto e della democrazia, Roma-Bari, Laterza \& Figli, 2 vols.

FISICHELLA, D., 1983: «Sul concetto di rappresentanza politica», en La rappresentanza politica, D. Fisichella (coord), Milano, Giuffrè editore, pp. 1-51.

Gallie, W. B., 1998: Conceptos esencialmente impugnados, trad. G. OrTiz Millán, Cuadernos de Crítica, núm. 49, México, UNAM.

GARCía Guitián, E., 2001: «Crisis de la representación política: las exigencias de la política de la presencia», en Revista de Estudios Políticos, núm. 111, enero-marzo, pp. 215-226.

— 2004: «El significado de la representación política», en R. DEL ÁGUILA TEJERINA (coord.), La representación en el Derecho, Anuario de la Facultad de Derecho de la Universidad Autónoma de Madrid, 8, pp. 109-120. 
Garrorena Morales, Á., 1991: Representación política y Constitución democrática, Madrid, Cívitas.

GORDILLO, A., 1978: La representación aparente: una aplicación del principio general de protección de la apariencia, Universidad de Sevilla, 1978.

Hart, H. L. A., 1968: Punishment and Responsibility, Oxford, Clarendon Press, 1968.

Hobbes, Th., 1980: Leviatán, trad. M. SÁnchez SARTo, México, Fondo de Cultura Económica. IBARRA, J., 2007: «Argumentos en materia de representación política», trabajo inédito.

Kelsen, H., 1993: Teoría pura del Derecho, trad. R. J. Vernengo (original alemán 1960), Porrúa.

LAPORTA, F., 1989: «Sobre la teoría de la democracia y el concepto de representación política: algunas propuestas para debate», en Doxa, núm. 6, pp. 121-141.

LeIBHOlZ, G., 1989: La rappresentazione nella democracia, a cura de S. FORTI, Milano, Giuffrè editore (original alemán de 1973).

Lifante Vidal, I., 2006: «Poderes discrecionales», en A. GARCÍA-FiguerOA (coord.), Racionalidad y Derecho, Madrid, Centro de Estudios Constitucionales, pp. 107-131.

MANIN, B., 1998: Los principios del gobierno representativo, trad. F. VALLESPín, Madrid, Alianza Editorial (original inglés de 1997).

Mansbridge, J., 2004: «Rethinking Representation», en The American Political Science Review, vol. 97 , núm. 4, pp. 515-528.

MiLL, J. S., 1985: Del gobierno representativo, trad. M. DE ITURBE, Madrid, Tecnos.

Perelman, Ch., y Olbrechts-Tyteca, L., 1989: Tratado de la argumentación, La nueva retórica, trad. J. Sevilla MuÑoz, Madrid, Gredos.

PitKin, H. F., 1985: El concepto de representación, trad. R. MONTORO Romero, Madrid, Centro de Estudios Constitucionales (original inglés de 1967).

PugliatTi, S., 1965: Studi sulla rappresentanza, Milano, Giuffrè editore.

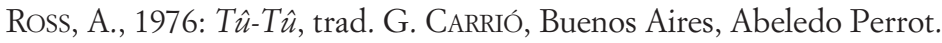

SARTORI, G., 1999a: Elementos de teoría política, versión de M. ${ }^{a}$ L. Morán, Madrid, Alianza Editorial.

— 1999b: «En defensa de la representación política», en Claves, núm. 91, pp. 2-6.

Weber, M., 1993: Economía y sociedad, trad. J. Medina Echevarría, J. Roura Farella, E. Ímaz, E. García Máynez y J. Ferrater Mora; México, Fondo de Cultura Económica.

Weissberg, R., 1978: «Collective vs. Dyadic Representation in Congress», en The American Political Science Review, vol. 72, núm. 2, junio, pp. 535-547.

Wellman, C., 1997: An approach to rights. Studies in the Philosophy of Law and Morals, Dordrecht, Kluwer. 